\title{
Prediction of tropical cyclone over North Indian Ocean using WRF model: Sensitivity to Scatterometer winds, ATOVS and ATMS radiances
}

\author{
Venkata B. Dodla ${ }^{1}$, Desamsetti Srinivas ${ }^{1}$, Hari Prasad Dasari ${ }^{2}$ and Chinna Satyanarayana Gubbala ${ }^{1}$
}

${ }^{1} \mathrm{~K}$ L University (India), ${ }^{2}$ King Abdullah University of Science and Technology (Saudi Arabia)

\begin{abstract}
Tropical cyclone prediction, in terms of intensification and movement, is important for disaster management and mitigation. Hitherto, research studies were focused on this issue that lead to improvement in numerical models, initial data with data assimilation, physical parameterizations and application of ensemble prediction. Weather Research and Forecasting (WRF) model is the state-of-art model for cyclone prediction. In the present study, prediction of tropical cyclone (Phailin, 2013) that formed in the North Indian Ocean (NIO) with and without data assimilation using WRF model has been made to assess impacts of data assimilation. WRF model was designed to have nested two domains of 15 and $5 \mathrm{~km}$ resolutions. In the present study, numerical experiments are made without and with the assimilation of scatterometer winds, and radiances from ATOVS and ATMS. The model performance was assessed in respect to the movement and intensification of cyclone. ATOVS data assimilation experiment had produced the best prediction with least errors less than $100 \mathrm{~km}$ up to 60 hours and producing pre-deepening and deepening periods accurately. The Control and SCAT wind assimilation experiments have shown good track but the errors were 150-200 km and gradual deepening from the beginning itself instead of sudden deepening.
\end{abstract}

\section{INTRODUCTION}

Tropical cyclones (also called hurricanes or typhoons), designated based on maximum sustained wind speeds exceeding $17 \mathrm{~m} / \mathrm{s}(62 \mathrm{~km} / \mathrm{h})$ and often not have attained wind speeds of $50 \mathrm{~m} / \mathrm{s}(180 \mathrm{~km} / \mathrm{h})$ are known for their devastation in terms of loss of lives and property. During the last decade, loss of lives has considerably decreased due to improvements in prediction although economic losses have substantially increased due to increased vulnerability to habitation, industrial and commercial activity near the coastline. Prediction of tropical cyclones is an important issue as early warning help disaster mitigation. The current state-of-art methodology is to use atmospheric models specifically designed and adapted for tropical cyclone prediction. While efforts are being continuous to improve the predictions, which comes under short range weather prediction, developments are focussed towards the design of model in terms of dynamics and physics, numerical methods and initial conditions. Accuracy in the specification of initial conditions is important in short range weather prediction using models as it is essentially an initial value problem. Since atmospheric models use a grid domain at which future state is obtained, data observations available at indiscrete locations have to be collocated to produce the best possible description of the initial state. Thus data assimilation has been an important in modeling methodology. Efforts grew from hand interpolations at Richardson (1922) to the present data computer oriented advanced methodologies such as 3DVAR and 4DVAR through objective analysis methods of Panofsky (1949), Cressman (1959), Barnes (1964) and Sasaki's (1969) optimum interpolation schemes. Developments of data assimilation have been excellently presented in the reviewed presented periodically (Daley (1991), Talagrand (1997), Kalnay (2003). For the prediction of tropical cyclones, prescription of initial state had severe limitations due to paucity of observations over oceans as tropical cyclones till the advent of satellite data and the developments in methodologies to assimilate satellite data. In recent times, several studies reported improvements in tropical cyclone prediction due to satellite data assimilation over all tropical oceans. A few of the recent studied are reviewed here. Xu et al. (2009) studied the impact of direct assimilation of ATVOS radiances data using the GSI-3DVAR system in the ARW model. Their results indicated that the track predictions of Hurricane Katrina have significantly improved after $36 \mathrm{~h}$ due to assimilation of ATOVS radiances. Srinivas et al. (2010) evaluated the impacts of satellite data and conventional observation assimilation in the prediction of a Bay of Bengal tropical cyclone and reported that assimilation of QSCAT winds, SSM/I winds, conventional surface and upper air meteorological observations through FDDA nudging produced better predictions of the movement and intensification of the tropical cyclone. Kanase and Salvekar (2013) reported improvements in the prediction of track of two cyclones (Aila 2009 and Jal 2010) with 24-hr forecast analysis nudging. Iyengar et al. (2014) predicted the Phailin cyclone using NCMRWF global forecast system and NCMRWF Unified Model (NCUM) and reported improvement of the track prediction with the Unified model in which 4DVAR has been

Remote Sensing and Modeling of the Atmosphere, Oceans, and Interactions VI, edited by Tiruvalam N. Krishnamurti, Madhavan Nair Rajeevan, Proc. of SPIE Vol. 9882,988213 - ( 2016 SPIE · CCC code: 0277-786X/16/\$18 doi: $10.1117 / 12.2223615$ 
used for the assimilation of global conventional and satellite data to improve the model initial conditions for tropical cyclone prediction. Greeshma et al. (2015) studied the impacts of data assimilation on tropical cyclone prediction through experiments with 8 cyclones over Bay of Bengal that had occurred during 2008 to 2013. They have used WRFDA system in the ARW model with assimilation of NCEP global PrepBUFR observations, Atmospheric Motion Vectors, Advanced Microwave Sounding Unit (AMSU) radiances. Their study of Phailin cyclone has shown improvements in prediction with the assimilation of both the convectional and satellite observations.

Although data assimilation studies have shown improvements in TC prediction, there is need to check and evaluate as and when new satellite data (for e.g., ATOVS, ATMS etc.) becomes available. For this reason, this study has been taken up to assess the impact of satellite data from ATOVS (Advanced TIROS (Television and Infrared Observation Satellite) Operational Vertical Sounder, Advanced Technology Microwave Sounder (ATMS) in the prediction of Bay of Bengal tropical cyclones through a case study of "Phailin" cyclone using ARW model. The details of the ARW model and experiments, description of satellite data sets used and the methodology of assimilation are presented in the next three sections. Results from model integrations with and without satellite data assimilation are presented in Section 5.

\section{DATA}

Different data sets, global analysis and forecast fields, satellite data from different sources and observation reports of the "Phailin" cyclone have been used in the present study. A brief description of the different satellite data that have been used for assimilation impact experiments is provided as follows.

(i) ATOVS Data: The ATOVS radiance data is provided by NESDIS, which comprises of Advanced Microwave Sounding Unit (AMSU) and High-resolution Infrared Sounder (HIRS/3 and 4). The AMSU-A is a multi-channel microwave radiometer used for measuring global atmospheric temperature profiles and for gathering information on atmospheric water in all of its forms, save small ice particles which are transparent at microwave frequencies. AMSU-A provides global coverage data at spatial scale of $48.05 \mathrm{~km}$ in diameter at nadir on the Earth. The AMSU-B or MHS (microwave humidity sounder) is a 5 channel microwave radiometer that measures radiation from a number of different layers of the atmosphere in order to obtain global data on humidity profiles. AMSU-B also provides global coverage data at $16.0 \mathrm{~km}$ diameter cell at nadir. The HIRS is a discrete stepping, line-scan instrument designed to measure scene radiance in 20 spectral bands to permit the calculation of the vertical temperature profile from the Earth's surface to about $40 \mathrm{~km}$. HIRS data has global coverage with Instantaneous Field of View of approximately 1.4 degrees in the visible and shortwave IR and 1.3 degrees in the longwave IR band that correspond to a spatial resolution of $20.3 \mathrm{~km}$ and $18.9 \mathrm{~km}$ in diameter, respectively, at nadir on the Earth. HIRS/3 sensor flies onboard NOAA-15,16,17 satellites, whereas HIRS/4 files on NOAA-18, NOAA-19 and MetOP satellites. AMSU-A sensor is available onboard NOAA-15,16,17,18,19 and MetOp satellites. AMSUB sensor flies onboard NOAA-15, 16 and 17.

(ii) MHS data: The Microwave Humidity Sounder (MHS) is a self-calibrating, cross-track scanning, five-channel microwave, full-power radiometer, operating in the 89 to $190 \mathrm{GHz}$ region. MHS channels $\mathrm{H} 1 \mathrm{at} 89.0 \mathrm{GHz}$ and H2 $(157 \mathrm{GHz})$ detect water vapour in the very lowest layers of the atmosphere and also observe the Earth's surface. H1 provides information on surface temperature and emissivity (in conjunction with AMSU-A data) and detects low altitude cloud and precipitation. Channels H5 (190.3 GHz), H4 (183.3 +/- $3.0 \mathrm{GHz})$ and H3 (183.3 +/$1.0 \mathrm{GHz}$ ) measure water vapour at increasing heights in the atmosphere. MHS flies on NOAA-18,19 and MetOp satellites.

(iii) ATMS data: The Advanced Technology Microwave Sounder (ATMS) instrument is the next generation crosstrack microwave sounder with 22 channels, providing atmospheric temperature and moisture for operational weather and climate applications. ATMS is a key instrument onboard Suomi National Polar-orbiting Partnership (NPP) satellite, collects microwave radiation from the Earth's atmosphere and surface all day and all night, even through clouds thus provides all-weather microwave temperatures and moisture data to produce atmospheric profiles. ATMS has the capability to provide a view inside and below clouds and can be used to produce images inside storms, including cyclones/hurricanes and provide invaluable data for understanding storms and making predictions up to five to seven days in advance of a severe weather event.

(iv) OSCAT: The OSCAT is a Ku-band conically scanning scatterometer system designed and built by the India Space Research Organization (ISRO)/Space Applications Center (SAC), launched aboard the Oceansat-2 satellite on September 23, 2009. The OSCAT ocean surface wind retrievals represent a 10 meter neutral stability wind. 
The OSCAT Level 1B and Level 2 products are provided to NOAA by ISRO on an orbit-by-orbit basis via EUMETSAT.

(v) ASCAT: The ASCAT ocean surface winds are a 10 meter neutral stability wind, processed and provided by NOAA/NESDIS utilizing measurements from ASCAT aboard the EUMETSAT MetOp satellites. The current geophysical model function (GMF) being used is CMOD5.5, where the GMF relates the normalized radar crosssection to the ocean surface wind speed and direction.

\section{Data used for present study}

The initial conditions and time varying boundary conditions were taken from NCEP GFS realtime data (http://www.ftp.ncep.noaa.gov/data/nccf/com/gfs/prod/) available at 1 degree resolution and 6-hour temporal resolution. The satellite radiance data is sourced from NCEP/EMC. The scatterometer winds are provided by NCMRWF GDAS observations. The background error covariance file (CV3) "be.dat" is being used for present study. The NCEP background error covariance is a global $\mathrm{BE}$ and can be used for any regional domain is computed based on NMC method (Parrish and Derber 1992).

\section{DESCRIPTION OF CYCLONIC STORM PHAILIN (8 TO 14) OCTOBER 2013}

Phailin cyclone was first located as a low pressure system over Andaman Sea on 7th October, as a depression 0300 UTC of 8 th with centre at $12 \mathrm{~N}, 96 \mathrm{E}$. The system moved in northwest direction attaining the stage of deep depression at 0000 UTC of 9th and recognised as a cyclonic storm at 1200 UTC of 9th October. The cyclonic system was declared as "severe cyclonic storm" at 0300 UTC and as "very severe cyclonic storm" at 0600 UTC of 10th October. The system intensified rapidly for the next 24 hours attaining T6.0 at 0300 UTC of 11 October. All along the Phailin cyclone moved in northwest direction, finally had its landfall around 1700 UTC of 12 October, 2013 near Gopalpur, Odisha state. After the landfall the intensity of the storm gradually decreased to a stage of deep depression at 1800 UTC of 13 October and depression at 0300 UTC of 14 October (IMD, 2014). The observed track of the cyclone PHAILIN as per the reports of India Meteorological Department (IMD) is shown in Figure 1.

\section{JBSERVED TRACK OF TROPICAL CYCLONE "PHAILIN"}

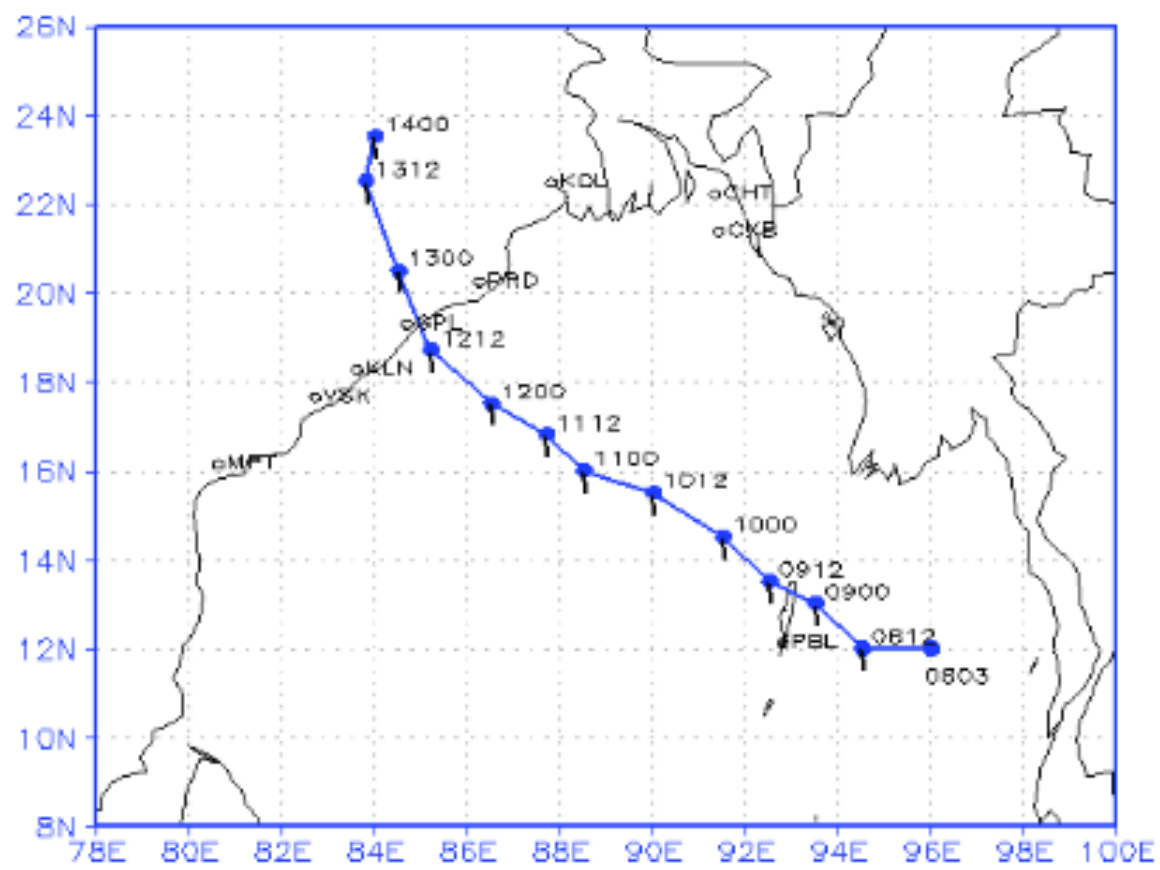

Figure 1. The track of Phailin during 0000 UTC 08 through 0000 UTC 14 October 2013 (IMD, 2014). 


\section{MODEL}

The Advanced Research Weather Research and Forecasting (ARW) modeling system, developed and sourced from NCAR, is used in the present study. This model is referred to as the next generation model after MM5, incorporating the advances in atmospheric prediction suitable for a broad range of applications. The modeling system has versatility to choose the domain region of interest, horizontal resolution, and interactive nested domains with various options to choose parameterization schemes for cumulus convection, planetary boundary layer, explicit moisture, radiation, and soil processes. ARW is designed to be a flexible, state-of-the-art atmospheric prediction system that is portable and efficient on available parallel computing platforms, and a detailed description was provided by Skamarock et al. (2008). ARW model is used in this study for its accurate numerics, higher-order mass conservation characteristics, and advanced physics. The model consists of fully compressible non-hydrostatic equations, and the prognostic variables include the three-dimensional wind, perturbation quantities of pressure, potential temperature, geopotential, surface pressure, turbulent kinetic energy, and scalars (water vapor mixing ratio, cloud water, etc.). The model equations are formulated using mass-based terrain following coordinate system and solved in Arakawa- $\mathrm{C}$ grid using Runge-Kutta third-order time integration techniques. The model has several options for spatial discretization, diffusion, nesting, and lateral boundary conditions. ARW modeling system supports horizontal nesting that allows resolution to be focused over a region of interest by introducing an additional grid (or grids) into the simulation with the choice of one-way and two-way nesting procedures. This model has been widely used by the scientific community for weather prediction including tropical cyclones. WRF Data assimilation system (WRFDA) is used for asssimilaiting the observations. WRFDA is the advanced version of the WRF's 3DVAR/ and 4DVAR module, which has the capability to assimilate several types of observations that include conventional surface, rawinsonde, aircraft, wind profiler, and atmospheric motion vectors and uniquely the radiances from all sensors directly through a forward radiative transfer model (Barker et al., 2012). In order to retrieve the track position, central sea level pressure and maximum wind, the Geophysical Fluid Dynamics Laboratory (GFDL) vortex tracker program (Bao et al., 2013) is used.

Model experiments: The ARW model has been adapted and designed to have two two-way interaction nested domains with resolutions of 15 and $5 \mathrm{~km}$ and with the inner domain covering the Bay of Bengal region (Figure 2). The configuration of the model is given in Table 1. Model integrations were performed for a 96-hr period and with a preforecast data assimilation period of 24 hours. A total of five model prediction experiments have been conducted, a control run (CNT) in which data assimilation was not adopted together with four data assimilation experiments with the assimilation of (i) ATOVS (AMSU-A, AMSU-B, HIRS) data (ii) ATMS data (iii) AMSU (AMSU-A, AMSU-B/MHS) radiances (iv) SCAT (ASCAT, OSCAT) winds. The details of numerical experiments are provided in Table 2. Considering the life cycle of the Phailin cyclone, assimilation period was chosen to be from 00 UTC of 8 October to 00 UTC of 9 October 2013 with five 6-hour cycles. Thus the model integrations have started at 00 UTC of 9 October 2013 and ended at 00 UTC of 13 October 2013 for all the four assimilation experiments and the control run.

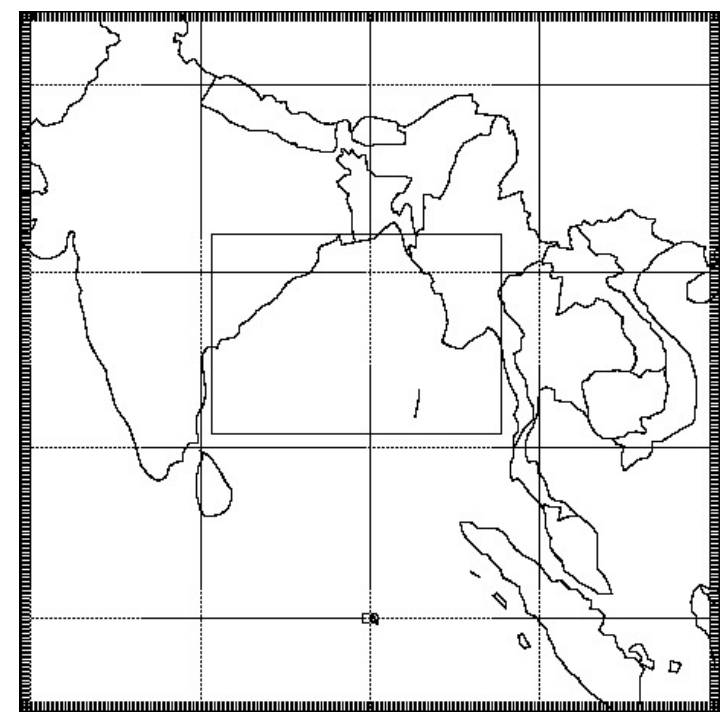

Figure 2. Model domains 


\section{RESULTS}

In this study, the prediction of Phailin cyclone over Bay of Bengal has been taken up to as a case study to assess the impacts of assimilation of different satellite data. Reports of the IMD indicated that the Phailin cyclone had attained the stage of "very severe cyclonic storm" (as per IMD nomenclature) with a sustained maximum wind speed of 120 knots and minimum central surface pressure of $940 \mathrm{hPa}$. In terms of track, the Phailin cyclone had a consistent northwest moment following general climatology with its landfall near Paradip, Odisha state on the east coast of India. The results from the five predictions experiments in terms of track (position and distance error) and intensity in terms of central surface pressure and maximum wind speed are presented in Figure 3.

Table 1: The details of model

\begin{tabular}{|c|c|c|}
\hline Model & \multicolumn{2}{|c|}{ WRF (ARW Core), WRFDA } \\
\hline Version & \multicolumn{2}{|l|}{3.6 .1} \\
\hline Dynamics & \multicolumn{2}{|c|}{ Primitive equation, non-hydrostatic } \\
\hline Vertical resolution & \multicolumn{2}{|l|}{48 levels } \\
\hline Domains & Domain1 & Domain2 \\
\hline Horizontal resolution & $15 \mathrm{~km}$ & $5 \mathrm{~km}$ \\
\hline Radiation & \multicolumn{2}{|c|}{$\begin{array}{l}\text { Dudhia scheme for shortwave } \\
\text { RRTM scheme for long wave }\end{array}$} \\
\hline $\begin{array}{l}\text { Initial and boundary } \\
\text { conditions }\end{array}$ & \multicolumn{2}{|c|}{ NCEP GFS Global Forecast } \\
\hline Cumulus convection & \multicolumn{2}{|c|}{ Kain-Fritsch (new Eta) scheme } \\
\hline Planetary boundary layer & \multicolumn{2}{|c|}{ Mellor-Yamada-Janjic TKE scheme } \\
\hline Explicit moisture & \multicolumn{2}{|l|}{ Lin scheme } \\
\hline Surface layer physics & \multicolumn{2}{|c|}{ Monin-Obukhov (Janjic) scheme } \\
\hline Land Surface & \multicolumn{2}{|l|}{ Noah LSM } \\
\hline
\end{tabular}

Table 2: Details of Numerical experiments

\begin{tabular}{|c|l|l|}
\hline Exp. & Name of the experiment & \multicolumn{1}{c|}{ Assimilated data } \\
\hline 1 & CNT & Control run - No assimilation \\
\hline 2 & ATOVS & AMSU-A, AMSU-B/ MHS, HIRS \\
\hline 3 & AMSU & AMSU-A, AMSU-B/ MHS \\
\hline 4 & ATMS & ATMS Radiance data \\
\hline 5 & SCAT & ASCAT and OSCAT winds \\
\hline
\end{tabular}




\section{a. Model prediction:}

The model predictions of the track (Figure 3a) show that the control run and two of the assimilation experiments (ATOVS and SCAT) have predicted northwest movement of the cyclone consistent with the observations. Two of the assimilation experiments, with the assimilation of only AMSU radiances data and only ATMS data had predicted the tracks with deviation to the left of the observations (i.e.) with the predicted cyclone moving more towards west of the observations. While the CNT and two assimilation experiments have predicted the landfall with an error of $150 \mathrm{~km}$, experiments - AMSU and ATMS did not predict a landfall as the predicted movements were slow and convoluted. Out of these three good prediction experiments, control run and SCAT wind assimilation experiments had shown slight deviation to the right of observed track while the ATOVS assimilation experiment had shown excellent coincidence of track up to 48 hours and with a slight deviation to the left of the observed track. Corresponding track vector distance errors are shown in Figure 3b. Of all these experiments, ATOVS assimilation had produced smaller track errors of less than $100 \mathrm{~km}$ up to 48 hours and best track up to 60 hours whereas the CNT and SCAT wind assimilation experiments had track errors in the range of 150 to $200 \mathrm{~km}$ beyond 30 hours. Despite the initial position error of $110 \mathrm{~km}$, ATOVS had track error of $20 \mathrm{~km}$ at 6 hours indicating a rapid adjustment of model environment to the in situ environment. In contrast, both the control run and SCAT winds assimilation experiments had initial position error of 25-30 km and the track errors rapidly increased to $175 \mathrm{~km}$ by 30 hours. These results indicate the importance of the assimilation profiles of temperature and humidity fields far more than surface wind assimilation. The near coincident tracks of the CNT and SCAT wind experiments indicate that NCEP GFS conditions at 1 degree resolution used in the present study, have a good representation of wind field congruent with the SCAT winds over the region.

The model predicted central surface pressure (CSP) along with IMD estimates are shown in Figure 3c. Experiment with assimilation of ATMS and AMSU did not show any intensification of the cyclone system. The time variation of CSP in the experiment with ATOVS assimilation shows the stages of pre-deepening for 24-hours followed by deepening and attainment of minimum CSP of $950 \mathrm{hPa}$ at 72 hours. In contrast, the CNT and SCAT wind assimilation experiments have shown gradual deepening from the initial time itself and reaching a minimum CSP of $930 \mathrm{hPa}$ at 72 hours. In comparison with IMD report, ATOVS experiment resembles more with the observations as the experiment could predict a predeepening period followed by rapid intensification although the predicted minimum CSP is higher by $10 \mathrm{hPa}$.

The predicted maximum wind speed along with IMD observations is shown in Figure 3d. As of the CSP variations, ATOVS experiment had the maximum wind speed (MW) of 55 knots at the initial time decreasing to 35 knots at 30 hours and then rapidly increasing to 85 knots at 66 hours. The CNT and SCAT wind assimilation experiments had wind speed increasing from 60 knots at the initial time to 100 knots at 60 hour. Although these three experiments underestimated the maximum wind speed, the time of attainment is reasonable with a delay of 6 to 12 hour only. Experiments with ATMS and AMSU did not show any increase of wind speed. The initial decrease during the first 24 hours as noted in the three good prediction experiments, ATOVS performs better in terms of the sudden increase of wind speed indicating rapid intensification of the cyclonic system as compared to a gradual increase in the CNT and SCAT wind assimilation experiments.

\section{b. Assimilated data:}

In this section a brief description of the bias correction, quality control and statistical metrics related to the assimilation of different satellite data are presented. Data from AMSU-A, AMSU-B, MHS and HIRS have been released after prepossessing for bias correction by NESDIS. The biases are dependent on satellite on satellite sensors are not constant for every channel. Figure 4a show a comparison of the biases of brightness temperature (BT) as a function of the channels for domain 1 region. The statistical parameters presented are the averaged values for all 5 cycles $(00,06,12,18$ UTC of 08 October, 00 UTC of $9^{\text {th }}$ October, 2013). It is noted that with bias correction, the innovation for most channels are confined to less than $0.5 \mathrm{k}$ which is quite smaller in magnitude as compared to no bias correction. These bias corrections are noted to be smaller than those derived by Xu et al. (2009) for their hurricane Katrina study.

The number of observations assimilated from different sensors is shown in Figure 4b. It is noted that Metop-1, Metop-2, NOAA-18 and NOAA-19 in channel 3, 4, 5 (MHS) less have the largest number of observations with 14000 for Metop1, 8000 for Metop-2, 8000 for NOAA-18, and 9000 for NOAA-19. This is in sharp contrast to other satellite data where in the assimilated observations are around 2000 for AMSU-A and AMSU-B of NOAA-15 and NOAA-16 and far less ( $\sim 100$ to 500$)$ for others. This clearly indicates the impact of humidity correction that is attributable to the large number observations from MHS. The root mean square errors (RMSE) for various satellite data are shown in Figure 4c. It is observed that the RMSE for MHS is 1.5 to 2 as compared to $5-6$ for AMSU-B of NOAA-16. RMSE for other data is insignificant as the number assimilation observations are quite small. 
For AMSU, MHS has the largest number of observations varying from 8000 (NOAA-18) to 12000 (NOAA-19, Metop1). The observations from AMSU-A and AMSU-B are relatively small with corresponding biases have a maximum of 0.5 to 0.7 for MHS (Metop-1, NOAA-18) and 0.3 for AMSU-A (Metop-2, NOAA-16, NOAA-18, NOAA-19). Corresponding RMSE for AMSU is 2.5k for MHS (Metop-1, Metop-2, NOAA-18, and NOAA-19) and 5 - 7k for AMSU-B (NOAA-16) (Figure 5).

Similar analysis for ATMS (Figure 6) shows that the number of assimilation observations is 10000-12000 for channel 9 and 10 and around 6000 for all other channels. The biases for ATMS are $0.1 \mathrm{k}$ for channel 22, 0.07k for channel 22 and less than $0.05 \mathrm{k}$ for all other channels. Corresponding RMSE are about $0.2 \mathrm{k}$ for channels up to 10 and $0.8-1.0 \mathrm{k}$ for channels 18 to 22 .
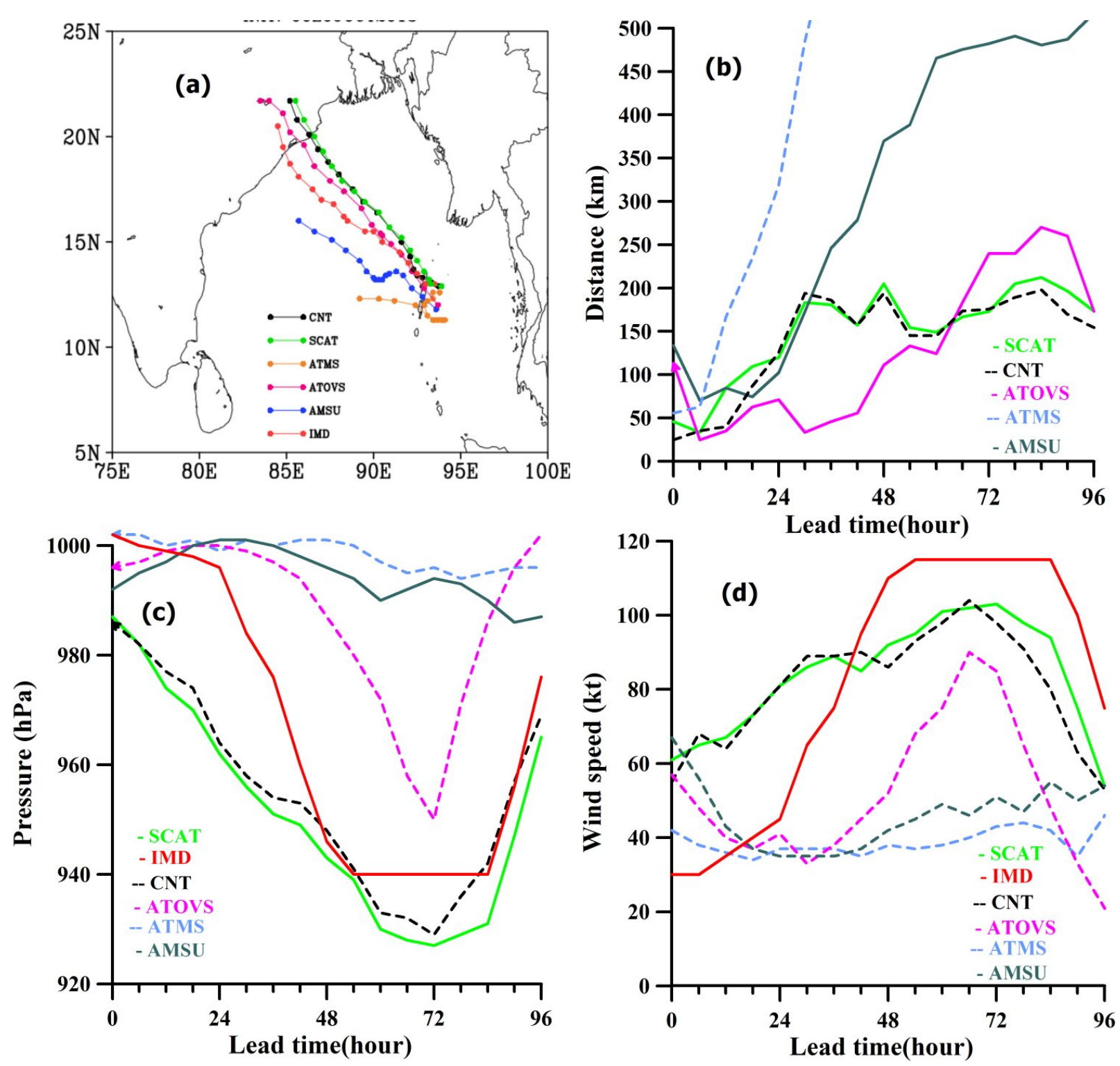

Figure 3. (a) Track positions of Phailin for different numerical experiments along with IMD estimates, (b) Vector Track errors $(\mathrm{km}),(\mathrm{c})$ central surface pressure $(\mathrm{hPa})$ and $(\mathrm{d})$ maximum surface wind speed $(\mathrm{kt})$. 


\section{c. Description of assimilated data fields:}

With a view to understand the impacts of assimilation of different data in the improvement of initial conditions, analysis of wind, temperature and humidity for the different experiments has been made. The differences between the CNT (considered as observation) and the assimilated fields at 0000 UTC of 9 October 2013 corresponding to the start of model integration have been computed. The results are presented as follows.

The wind at $850 \mathrm{hPa}$ in the CNT run shows anticlockwise rotating winds around a centre at $12.9 \mathrm{~N}, 93.7 \mathrm{E}$ with strength exceeding $30 \mathrm{~m} / \mathrm{s}$ with a clearly defined inner flow all features depicting a cyclonic system (Figure 7a). The difference wind plots (Figure $8 \mathrm{a}, \mathrm{b}, \mathrm{c}, \mathrm{d}$ ) show that all assimilation fields have stronger winds at the centre, both ATOVS and AMSU have stronger wind field in the outer environment, especially to the north and weaker winds in the south indicating a stronger gradient in these two experiments. Contrastingly ATMS and SCAT experiments have negative values (that indicate weaker winds) all around the centre. These features suggest stronger asymmetries of the cyclone structure in the ATOVS and AMSU experiments. The temperature fields at $850 \mathrm{hPa}$ for CNT shows warmer core region at the center of the storm with temperature around $20^{\circ} \mathrm{C}$ (Figure $7 \mathrm{~b}$ ). The temperature difference fields at $850 \mathrm{hPa}$ shows positive values of 2-5 degrees near the centre and negative values all around in the ATOVS (Figure 9a) and AMSU (Figure 9b) experiments and negligible negative values throughout in the ATMS (Figure 9c) and SCAT (Figure 9d) experiments. These features indicate warmer core in the ATOVS and AMSU assimilations. The relative humidity (RH) fields in the CNT run show typical humidity structure with near saturation around the cyclone centre and spiralling humid inflow (Figure 7c). The differences in RH field of ATOVS, AMSU and ATMS show higher humidity ( $>50 \%)$ over a larger area around the core of the cyclone system and lesser values in around the near core (Figure $10 \mathrm{a}, \mathrm{b}, \mathrm{c}$ ), whereas SCAT shows negligible smaller humidity differences (Figure 10d). These features along with the noted higher humidity observation assimilation indicate a clear significant impact of humidity observations leading to contrasting humidity distributions with higher humidity in the outer environment that have also contributed to variations in the temperature and wind fields. A comparison of differences (assimilation CNT- experiment) in the vertical profiles of wind speed $(\mathrm{m} / \mathrm{s})$, temperature (k), humidity (\%) and absolute vorticity (/s) fields at a single location near the core of the cyclone is depicted in Figure 11. The negative values show that the sensitivity experiments are deviated from the CNT positively (CNT-EXP). The differences in wind speed shows that the speed lies between $\pm 5 \mathrm{~m} / \mathrm{s}$ upto $700 \mathrm{hPa}$, negative upto $400 \mathrm{hPa}$ level and having large variations afterwards (Figure 11a). The differences in temperatures shows that higher temperatures throughout the troposphere are observed; SCAT has lower temperatures at middle and upper levels; ATOVS had warmer middle levels and cooler upper levels; and AMSU had been warmer in the middle and upper levels (Figure 11b). These indicate strong contrasting differences between the different assimilations for the impact on temperature field. Considering vertical humidity fields, large differences exist above $750 \mathrm{hPa}$ level $(<-20 \%)$ otherwise the variations in the lower troposphere are less than $10 \%$ (Figure 11c). These profiles show that the radiance assimilation have larger impacts in modifying the humidity fields than any other fields and subsequently changes are observed in other fields. Similarly the vertical variations of absolute vorticity shows that the variations for SCAT shows negative and the remaining radiance assimilation experiments on the other hand deviated on the positive side, which describes the reduction of radial component of wind in the radiance assimilation experiments. This is a preliminary analysis and more detailed analysis will be made to ascertain the differences. 

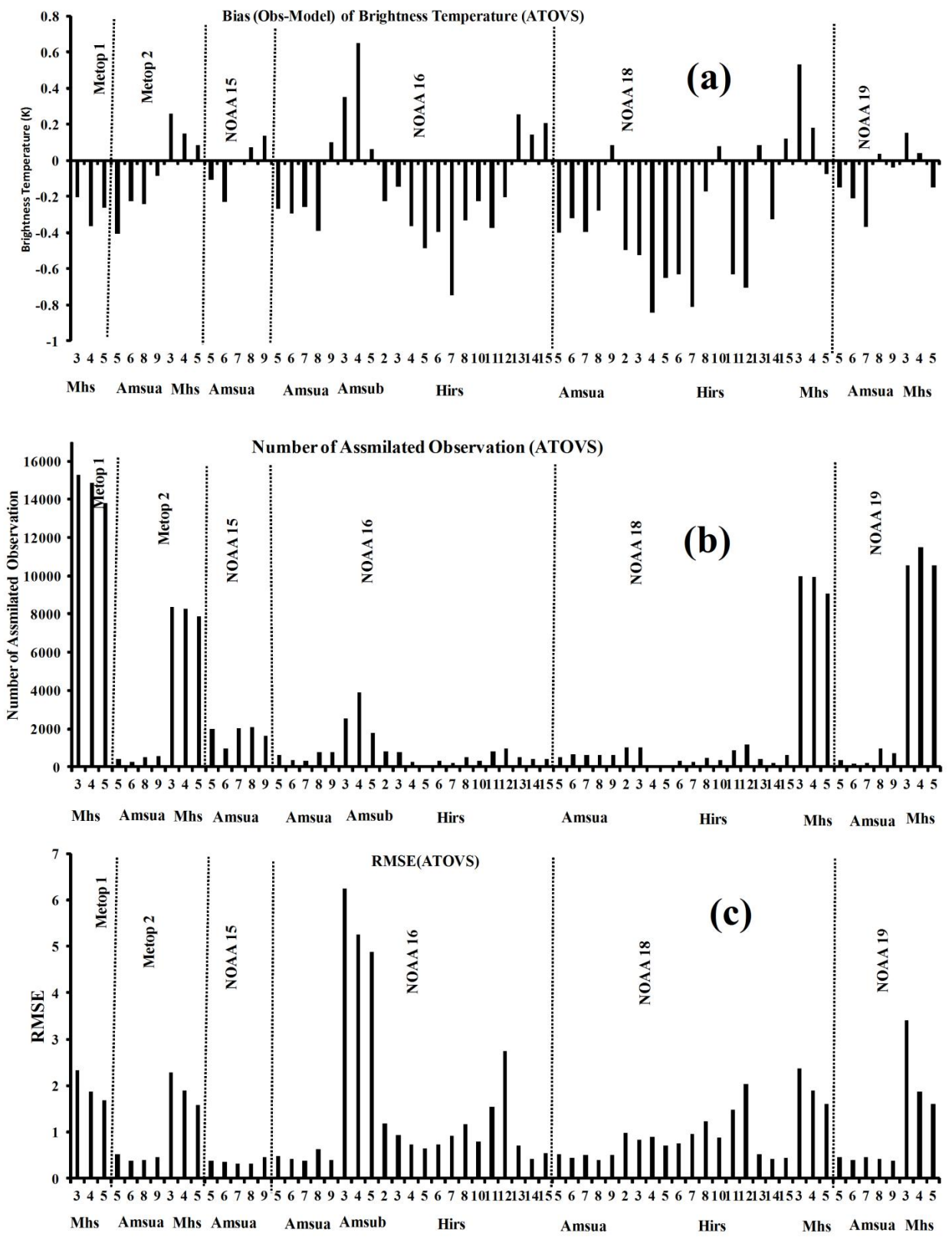

Figure 4. The averaged (a) Innovation (OBS minimus Model) of brightness temperature (k), (b) The number of assimilated observations and (c) RMSE of BT (k) for different channels of AMSU onboard different satellites. 

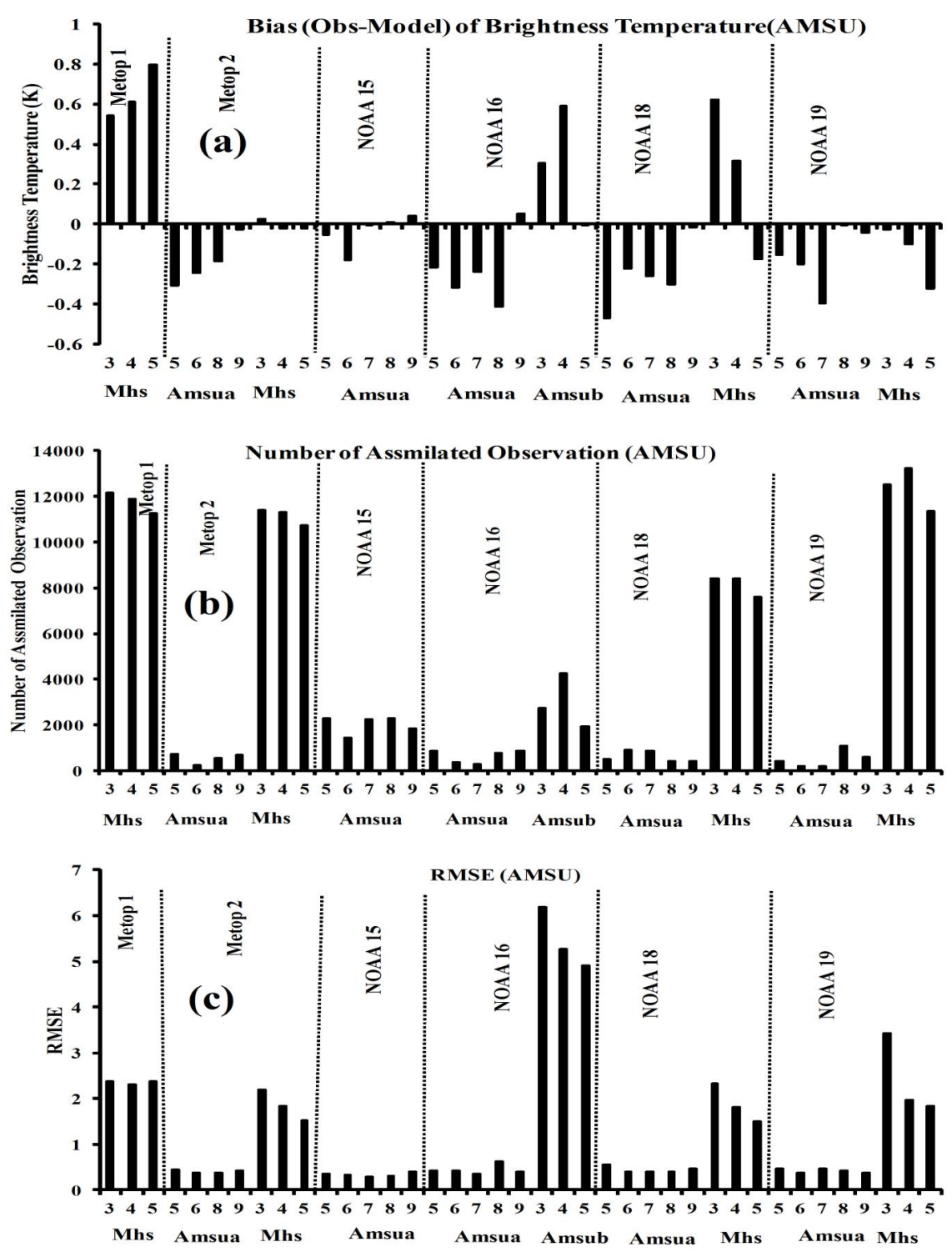

Figure 5. Same as Figure 4, but for AMSU.

ATMS

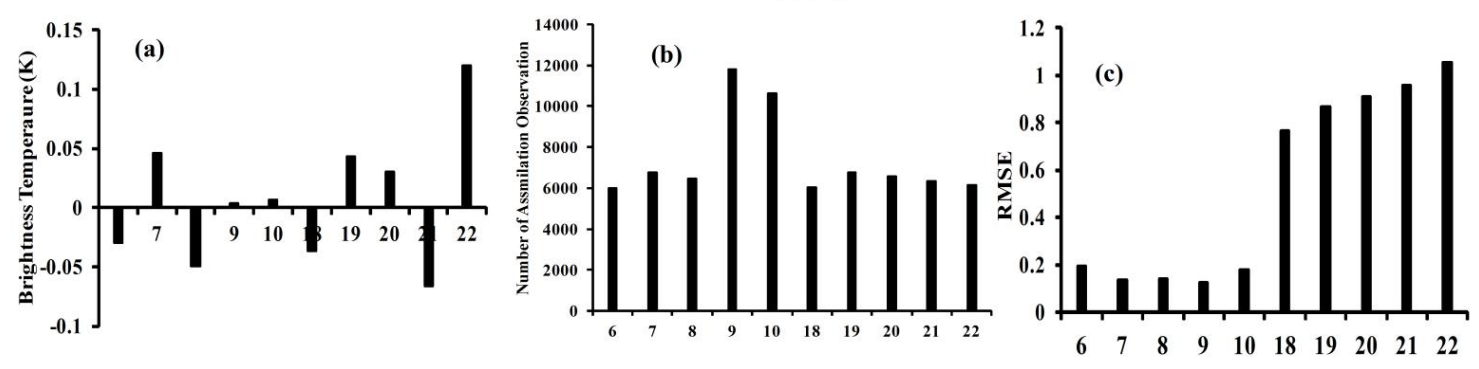

Figure 6. Same as Figure 5 but for ATMS. 

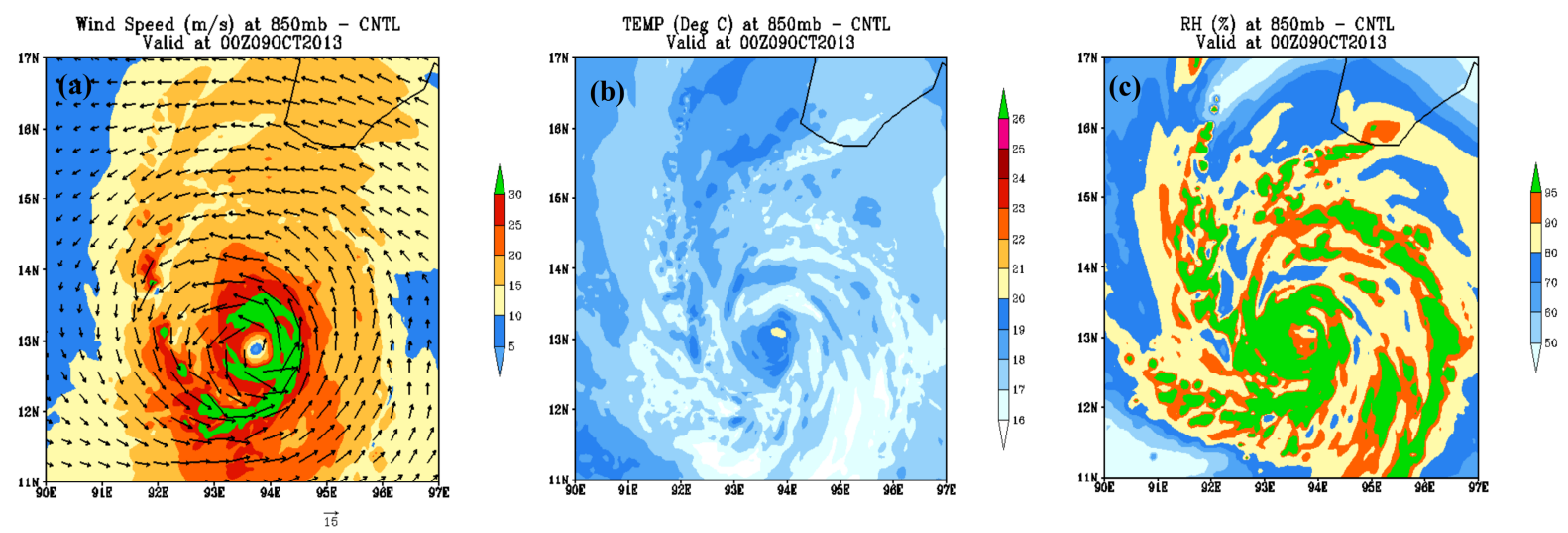

Figure7: Spatial Distribution of (a) Wind (m/s) ; (b) Temperature (Deg C) and (c) Relative humidity (\%) of CNT valid at 0000 UTC of $9^{\text {th }}$ October, 2013.
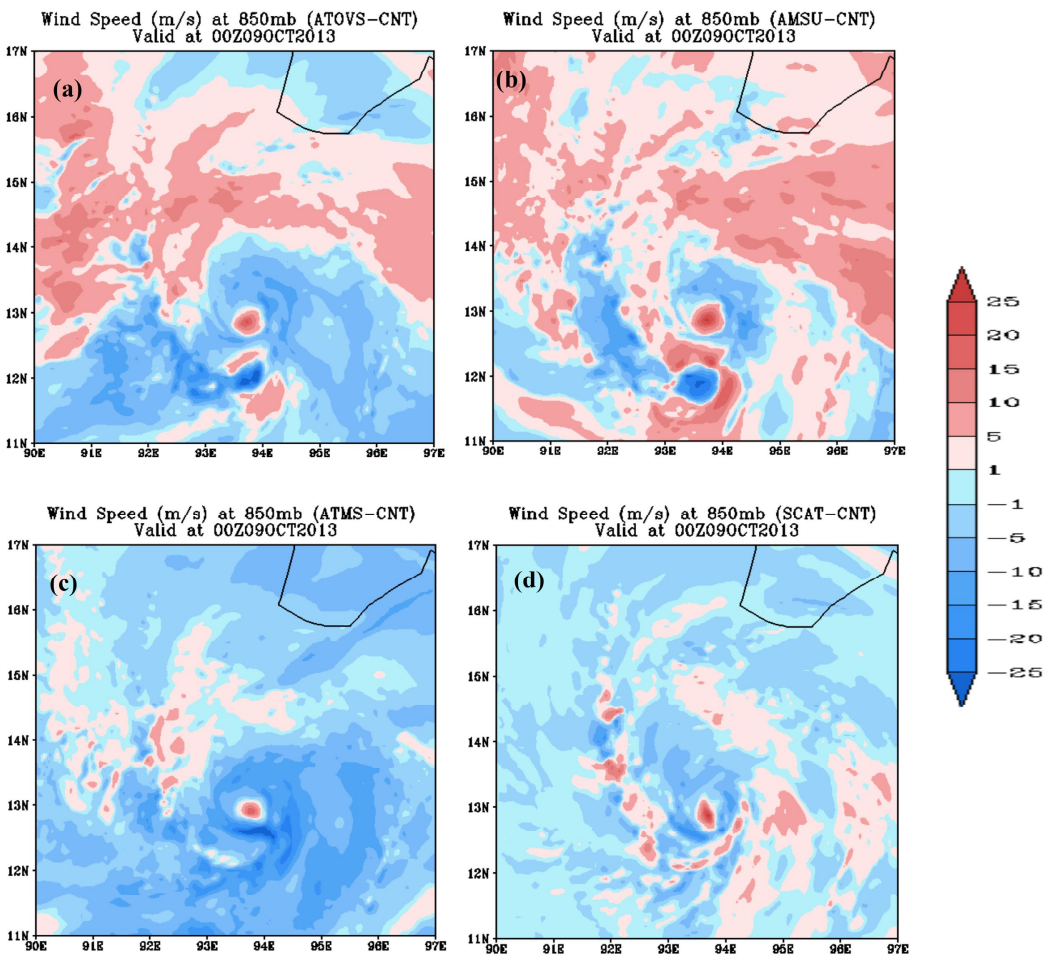

Figure 8: Spatial Distribution of differences in wind speed $(\mathrm{m} / \mathrm{s})$ at $850 \mathrm{hPa}$ for (a) ATOVS; (b) AMSU; (c) ATMS and (d) SCAT valid at 0000 UTC of $9^{\text {th }}$ October, 2013. 

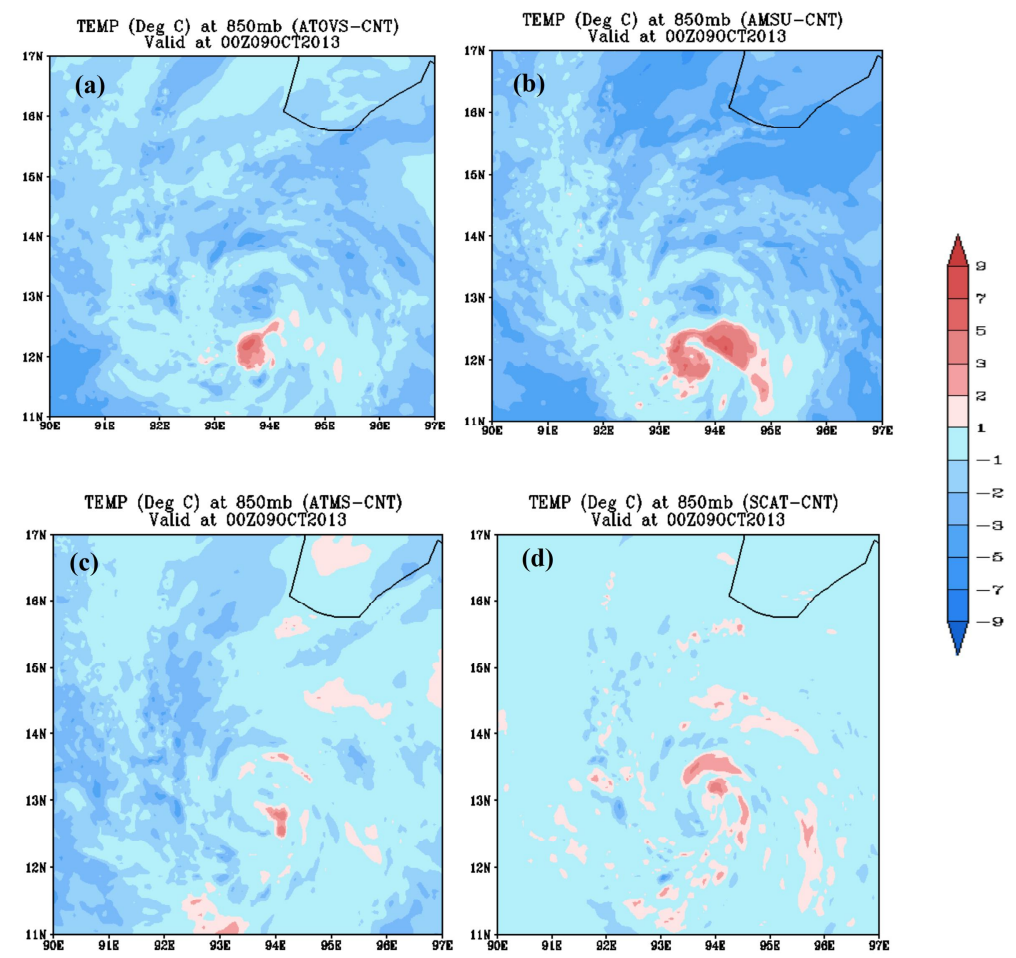

Figure 9: Spatial Distribution of differences in temperature (deg C) at $850 \mathrm{hPa}$ for (a) ATOVS; (b) AMSU; (c) ATMS and (d) SCAT valid at 0000 UTC of $9^{\text {th }}$ October, 2013.
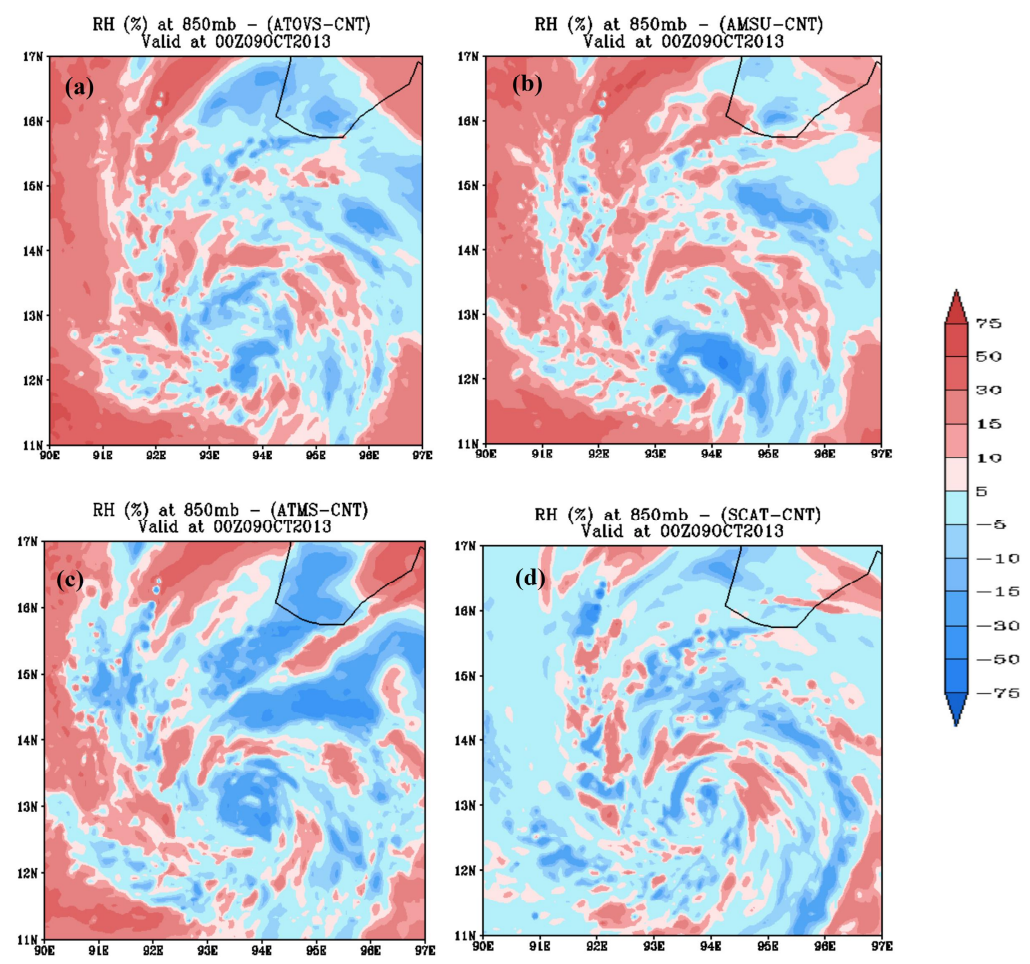

Figure 10: Spatial Distribution of differences in relative humidity (\%) at $850 \mathrm{hPa}$ for (a) ATOVS; (b) AMSU; (c) ATMS and (d) SCAT valid at 0000 UTC of $9^{\text {th }}$ October, 2013. 

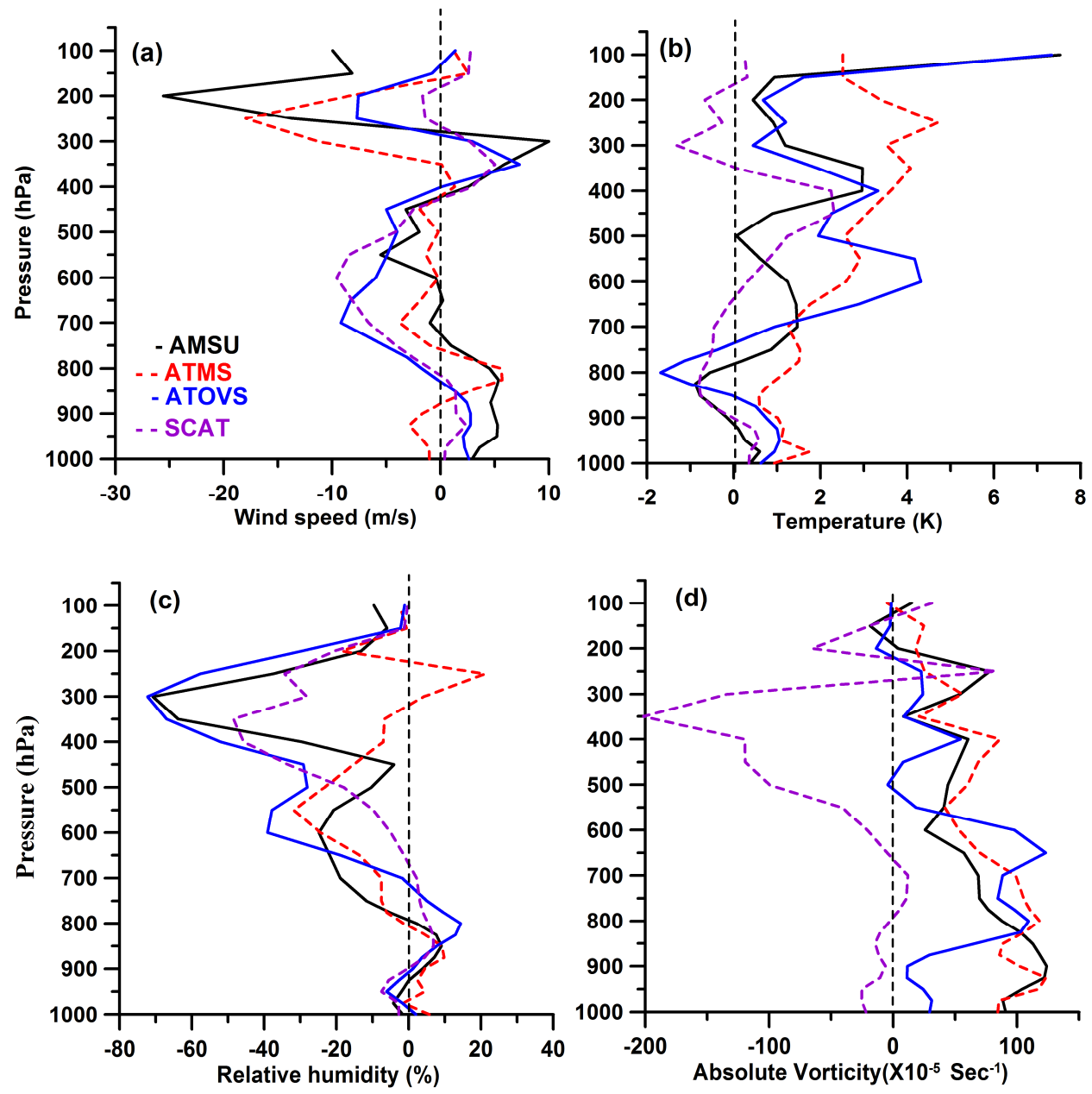

Figure 11: Vertical profile differences of (a) Wind speed (m/s) (b)Temperature (deg C), (c) Relative humidity (\%) (d) Absolute vorticity valid at 0000 UTC of $9^{\text {th }}$ October, 2013.

\section{SUMMARY}

In this study, the impact of satellite data assimilation on tropical cyclone prediction through improvement of initial conditions using ARW model is studied. Phailin cyclone that had its life cycle over Bay of Bengal during $9-13$ October 2013 has been taken up as a case study, as the cyclone attained the stage of "very sever cyclonic storm" and had a consistent northwest movement. ARW model is adapted and designed to have nested two domains and with inner domain predictions at 5-km resolution. ATOVS radiance data that include data from AMSU-A, AMSU-B or MHS and HIRS; Advanced Technology Microwave Sounder (ATMS); and scatterometer (SCAT) from OSCAT and ASCAT winds have been assimilated through different model prediction experiments to understand the nature of observations in terms of number and quality and the impact of wind, temperature and humidity fields on the prediction of cyclone track and intensification. Assimilation was done for 24-hours, considered as pre-forecast period, with 5-cycles of assimilation and prediction on was carried out for 96-hours. The evolution of Phailin cyclone from four satellite data assimilation experiments and an experiment without assimilation, denoted as "control" run (CNT) was analysed to evaluate track and intensity errors. 
ATOVS data assimilation experiment had produced the best prediction with least errors less than $100 \mathrm{~km}$ up to 60 hours. Control run and Scat wind assimilation experiments have shown good track but the errors were 150-200 km. ATMS and AMSU experiments did not show any intensification beyond the initial intensity and the track errors were largest with deviated track and no predicted landfall. ATOVS produced the best prediction for intensification, producing predeepening and deepening periods accurately. Control and Scat wind experiments also predicted the intensification but with gradual deepening from the beginning itself instead of sudden deepening which is a noted characteristic of tropical cyclones.

An analysis of the characteristics of assimilation data has shown that Metop-1, Metop-2, NOAA-18 and NOAA-19 in channel 3, 4, 5 (MHS) have the largest number of observations thus indicating the impact of humidity correction that is attributable to the large number observations from MHS.

Analyses of the differences in the initial wind, temperature and humidity fields at $850 \mathrm{hPa}$ level and vertical variations at the tropical cyclone central region has shown that ATOVS and ATMS experiments had shown impacts on the outer environment humidity, and corresponding warmer central region and stronger core winds. Although humidity assimilation has been noted to be important, corresponding impacts on temperature and winds had been seen.

This study clearly brings out the impacts of satellite data assimilation towards improvements in the description of initial conditions that lead to better prediction of tropical cyclone evolution in terms of movement and intensification. The assimilation and model experiments also indicate the usefulness of 3DVAR assimilation methodology and ARW model in tropical cyclone prediction.

\section{ACKNOWLEDGMENTS}

The authors thank Dr. Zhang and Dr. Vijay Tallapragada for providing the observations and satellite data for the assimilation experiments in the study and acknowledge the data source from Environmental Modeling Center, NOAA, USA. The authors also thankful to Dr.V.S.Prasad, NCMRWF for providing the scatterometer wind observations during the study period.

\section{REFERENCES}

Bao, S., Stark, D., Bernardet, L., "Users' guide for the Community release of the GFDL Vortex Tracker," The Developmental Testbed Center,National Centers for Environmental Prediction (NCEP), p24 (2013).

Barker, D., Huang, X.-Y., Liu, Z., Auligné, T., Zhang, X., Rugg, S., Ajjaji, R., Bourgeois, A., Bray, J., Chen, Y., Demirtas, M., Guo, Y.-R., Henderson, T., Huang, W., Lin, H.-C., Michalakes, J., Rizvi, S., and Zhang, X., "The Weather Research and Forecasting Model's Community Variational/Ensemble Data Assimilation System: WRFDA,” Bull. Amer. Meteor. Soc., 93, 831-843 (2012).

Barnes, S, L., "A technique for maximizing details in numerical weather map analysis," J Appl Meteor 3,395-409 (1964).

Cressman, G, P., “An operational objective analysis system,” Mon Wea Rev 87:367-374 (1959).

Daley, R., (1991) Atmospheric data analysis. Cambridge University Press, Cambridge

Greeshma, M, M., Srinivas, C, V., Yesubabu, V., Naidu, C. V., Baskaran, R., and Venkatraman, B.. "Impact of local data assimilation on tropical cyclone predictions over the Bay of Bengal using the ARW model," Ann. Geophys., 33, 805-828 (2015).

IMD (India Meteorological Department) "Report on Cyclonic Disturbances over North Indian Ocean during 2013," Met. Monograph No. ESSO/IMD/RSMC-Tropical Cyclones Report No. 01 (2014)/5, RSMC-Tropical Cyclones, India Meteorological Department, Ministry of Earth Sciences, Govt. of India, New Delhi, p273 (2014).

Iyengar, G., Ashrit, R., Ashish, A., Sharma, K., Gupta, D, M., Rajagopal, N, E., and Basu, S., "Improved prediction of cyclone Phailin (9-12 October 2013) with 4DVAR assimilation," Current Science, 107 (6), 952-954 (2014).

Kalnay, E., "Atmospheric modeling, data assimilation and predictability," Cambridge Univ Press, Cambridge, p 341 (2003). 
Kanase R, D., and Salvekar, P. S., "Role of Four-Dimensional Data Assimilation on Track and Intensity of Severe Cyclonic Storms," ISRN Meteorology, vol. 2013, Article ID 972713, 8 (2013). doi:10.1155/2013/972713

Panofsky, H, A., Objective weather-map analysis. J Appl Meteor 6:386-392 (1949).

Parrish, D. F., Derber, J, C., "The National Meteorological Center's spec- tral statistical interpolation analysis system," Mon Wea Rev,120, 1747-63 (1992).

Richardson, L, F., "Weather prediction by numerical processes," Cambridge University Press. Reprinted by Dover (1965, New York).With a New Introduction by Sydney Chapman, xvi+236 (1922).

Sasaki, Y, K., "Proposed inclusion of time-variation terms, observational and theoretical in numerical variational objective analysis," J Meteor Soc Japan 47:115-203 (1969).

Srinivas, C. V., Venkatesan, R., Vesubabu, V., and Nagaraju, C., "Impact of assimilation of conventional and satellite meteorological observations on the numerical simulation of a Bay of Bengal Tropical Cyclone of Nov 2008 near Tamilnadu using WRF model," Meteor. Atmos. Phys., 110, 19-44 (2010).

Talagrand, O., “Assimilation of observations, an introduction,”.J Meteorol Soc Japan 75 (1B):191-209 (1997).

Xu, J., Rugg, S., Horner, M., and Byerle, L, "Application of ATOVS Radiance with ARW WRF/GSI Data Assimilation System in the Prediction of Hurricane Katrina," The Open Atmospheric Science Journal, 3, 13-28 (2013). 